\title{
Attachment in Structuring Information in Students' Mental Representations
}

\author{
Nina Kozárová, Juraj Komora \\ Constantine the Philosopher University in Nitra, Faculty of Education, Dražovská cesta 4, \\ Nitra 949 74, Slovakia
}

\begin{abstract}
This study examines structuring of information in education and its attachment to mental representations of students. Structuring of information is perceived as a psycho-didactic issue. Research methods used within this study include experimentation and testing of concept mapping. The research sample consisted of 96 participants. The analysis of results showed that non-linear structuring of information improved students' results in experimental groups in the researched parameter: operationalization.
\end{abstract}

Keywords - concept map, semantic network, mental representation of information, text structuring.

\section{Introduction}

Thinking is the essence of human existence. Undoubtedly, it is supreme outcome of the human evolution. However, it is impossible to holistically communicate all human knowledge accumulated and summarized so far to students. Students would not possibly be able to absorb the immense volume of knowledge (representing the current advancement in scientific areas) since this is often too abstract. Therefore, educational content has to be selected to a degree that is a representative selection of all knowledge.

DOI: $10.18421 /$ TEM94-50

https://doi.org/10.18421/TEM94-50

Corresponding author: Nina Kozárová, Constantine the Philosopher University in Nitra, Faculty of Education, Dražovská cesta 4, Nitra 949 74, Slovakia.

Email: nkozarova@ukf.sk

Received: 21 June 2020.

Revised: 22 October 2020.

Accepted: 27 October 2020.

Published: 27 November 2020.

(c))BY-NC-ND (C) 2020 Nina Kozárová \& Juraj Komora; published by UIKTEN. This work is licensed under the Creative Commons Attribution-NonCommercial-NoDerivs 4.0 License.

The article is published with Open Access at www.temjournal.com
Simultaneously, this knowledge has to be adequate within the context of learners' cognitive levels. In contemporary education practice it is vital to assist students in their capacity to independently create learning strategies that will help make acquired information part of their everyday life. We agree with [1] statement that "the brain tends to consider a fact or idea 'useful' in the long term only if it comes across it regularly".

This can be seen as a key reason why few students can master and apply all knowledge acquired in education after their schooling. Very often teachers present knowledge using words combined into various types of sentences. Sentences are then organized to transmit individual opinions and thoughts. We disagree with the practice of teachers who do not to teach students how to apply acquired knowledge in their life and mutually link pieces of information into a branched semantic network. It is important to teach students how to work independently, and code and decode the information they use, either in spoken or written language. We believe one can understand and interpret the world precisely based on connecting pieces of information and identifying mutual relations and correlations.

This study has several aims. The first is to analyze and set out the main pillars of constructivist teaching methods. We target individual learning strategies and their specification. No less importantly, we analyze concept mapping and its role in teaching. We draw inspiration not only from theoretic knowledge in pedagogy but also research on concept mapping that points to increased efficiency of the educational process once concept mapping is implemented in teaching. The main goal is to analyze and compare the conceptual level of how the information (curriculum) is structured and what kind of attachment it has to mental representations in students of secondary education.

\section{Constructivist Teaching}

We retrieve information through our senses, often without verbal coding. Students thus create ideas they can use without verbal expression. However, if we require them to explain the idea thus acquired, 
they first need to code it through concepts they know, i.e. concepts with a stable position in their internal knowledge structure [2], [3].

Our conclusion is that even if every situation provides the same information to students, they cannot perceive all of it simultaneously. Therefore, they spontaneously choose those pieces of information they assess as easier to perceive, not realizing how much they may be needed. This suggests that each student will receive different information from the same situation. The level of selection in students depends on their experience the more experienced they are in selecting information, the better they can set their filter. That means that two students receive the same set of information, but they process it differently - i.e. the outcome of cognition is different in most cases.

In educational practice, we need to analyze key information for understanding the presented curriculum (that which is desirable to know), and select supplementary information that students may acquire later.

The imperative of contemporary education should not only be to lead students to acquire knowledge facilitated by other people, but also to organize basic information so that it creates a stable support system for their internal knowledge structure.

[4] build on their basic thesis to set out the main pillars of constructivist learning methods:

- The student as learner constructs his/her knowledge based on analyzing and facilitating the meaning of the acquired knowledge

- Knowledge is constructed theoretically by the learner through analysis and explanation of things he/she does not understand

- Knowledge is constructed physically by the learner's active and focused attitude during knowledge acquisition

- Knowledge is constructed symbolically by the learner creating schemes and models about the acquired knowledge

Research that quantifies the benefits and positive impact of constructivism in educational practice is very limited. However, there are many arguments that also point to its theoretical advantages. The introduction of constructivist demands to educational practice primarily represents an emphasis on individual interpretation schemes of students, since students develop their learning mechanisms through their individual active construction of knowledge.

Constructivism in education can be understood as reflected education, the construction and reconstruction of students' internal knowledge systems the focus on supporting student's active understanding and stimulation of higher cognitive functions. Constructivist education is not the transfer and subsequent internalization of readymade knowledge, but rather the construction of one's own meanings for one's knowledge and its supplementary organizing into an internal knowledge structure.

Under this approach, teaching and learning is understood as a constructivist process, since learning with comprehension may bring more efficient results through relevant practical experience. Traditional teaching is the handing over of information that the students are to learn. Traditional teaching is not necessarily mechanical - quite the contrary, it can be meaningful if the student reacts to the new information and processes it. If the student links new information with previous knowledge, the internal knowledge structure is activated, and it can be concluded that this traditional teaching was meaningful. If however student only memorized information facilitated by the teacher without attempting to identify connections and mutual links, the outcome is clearly mechanical learning.

Our understanding of the constructivist approach to education is that constructivist education focuses on updating previous cognition, the active role of the learner, the focusing of attention on activities that induce thinking, challenging situations that stimulate critical and creative thinking, an emphasis on the social and cultural context in acquiring and understanding new information, the construction of schemes and models of acquired knowledge, and modification of an internal structure based on experience.

Content-related changes in education from the perspective of constructivist teaching should primarily focus on:

- Reduction of emphasis on facts in the curriculum (the aim of learning is to create a flexible cognition basis, which will be a platform for further thinking);

- Changes of the teacher's role in the educational process (the teacher is not only a facilitator of knowledge, rather he/she should be mindful of the comprehensive development of students);

- Emphasizing development of interdisciplinary links among subjects (taking into consideration comprehensiveness and meaningfulness in learning, and the easier retention of information);

- Reduction of excessively abstract parts of curriculum (high level of abstraction in information is typical for the scientist paradigm in education);

- Applying curriculum into everyday life (an excessive amount of theoretical information leads students to superficial learning and learning strategies that do not enhance creative and critical thinking). 


\section{Learning Strategies}

Whatever we know, we have to have learned sometime. Many of us, however, still do not know how to learn effectively. We believe this is what schools should aim at, since the ability to learn is critically important for our lives. Most current school reforms primarily aim at enhancing education process effectiveness and increasing the quality of students' outputs, underlining the importance of success in the labour market. Students do not need to retain all data to think, but it is not realistic for them to think about something that is not in their memory. Therefore, the golden mean has to be pursued finding a balance between what has to be retained in one's memory and what can be modified or supplemented through one's own thinking or found in some source of knowledge.

It appears that education pays but little attention to identifying teaching methods or strategies that enhance competencies for effective learning. The question what should a successful, but first and foremost, functional learning model look like should be constantly considered. It seems schools in our country still do not understand that teaching is not only about the information contained in texts, i.e. it is inappropriate to study primarily through texts. The human brain simply cannot understand and grasp only abstract information from a text, since learning occurs through sensory codes. When an idea is linked to a picture we talk about visual predicates, and when it is linked to a sound we talk about auditory predicates.

For the versatile development of students, the educational process has to apply a broad array of teaching strategies. The latter can help them to acquire effective tools for learning with comprehension, problem solving, and presentation of their ideas. These are furthermore an important part of motivation - students are active partners in education and involved in classroom work. Moreover, learning and teaching are not stereotyped activities (strategies create the dynamics of teaching; the content is its static element). Applying diverse strategies can lead the students to choose the right learning methods, and develop metacognition and self-regulation (which creates one's cognitive integrity). Last but not least, we can improve students' attitude to a subject, support long-term retention of information in the memory, expand their vocabulary and enhance students' creativity.
We have to teach students to think in a broader context, read with comprehension, seek solutions to problems, and present results achieved through their own efforts. We believe the way information is processed, hand in hand with the quality of perception, is a key determinant in shaping or modifying specific learning strategies, since those factors have significant impact on representing, coding, and organizing information in functional wholes, and on work with students' mental representations. It is very challenging for students to modify their learning strategies, since learning is often connected with many and diverse habits and automatized activities.

[5] categorize the most frequently-used learning strategies into three groups as shown below:

Table 1. Learning strategies

\begin{tabular}{|c|l|}
\hline \multirow{4}{*}{ Rehearsal } & Taking verbatim notes \\
\cline { 2 - 2 } & Underlining text \\
\cline { 2 - 2 } Elaboration & Memorizing words and definitions \\
\hline \multirow{4}{*}{ Organizational } & Summarizing \\
\cline { 2 - 2 } & Answering questions \\
\cline { 2 - 2 } & Note making \\
\cline { 2 - 2 } & Selecting main idea \\
\cline { 2 - 2 } & Representation (mapping) \\
\cline { 2 - 2 } & Developing solution \\
\hline
\end{tabular}

Rehearsal strategies are efficient for learning basic/key information. However, they do not allow retention of complex information due to their main limitation - new information or acquired knowledge cannot be sufficiently connected to information that was already in the individual's knowledge structure.

Elaboration strategies help retention by linking new information to information with a stable position in the individual's internal knowledge structure. Therefore, such strategies facilitate more comprehensive learning. Sometimes it is challenging or even impossible for students to organize or reorganize acquired knowledge. The aforementioned authors believe that organizational strategies may be helpful since they enable the students to outline a template for better organization of information.

When discussing learning and teaching strategies, [6] also include the following: structuring of information, instructional explanation, concept mapping, summarizing, synthesis, mnemotechnical tools, organizing of information, analogies, demonstrations, and organizing and sequencing of information to encourage its optimal elaboration. Based on the literature review for the purposes of this research, we present the following teaching strategies: 
Table 2. Specification of teaching

\begin{tabular}{|l|l|}
\hline $\begin{array}{l}\text { Text } \\
\text { orientation }\end{array}$ & $\begin{array}{l}\text { Activation and consolidation of the } \\
\text { individual's relevant information / } \\
\text { getting a first idea about the content } \\
\text { and scope of studied information }\end{array}$ \\
\hline Memorizing & $\begin{array}{l}\text { Memory is considered one of the key } \\
\text { categories of successful learning / the } \\
\text { aim of comprehension is primarily to } \\
\text { facilitate easier and more effective } \\
\text { retention of information }\end{array}$ \\
\hline $\begin{array}{l}\text { Information } \\
\text { coding and } \\
\text { decoding }\end{array}$ & $\begin{array}{l}\text { Acquired information is recoded into } \\
\text { more retainable form; based on that } \\
\text { the individual organizes all } \\
\text { information more easily into the } \\
\text { internal knowledge structure }\end{array}$ \\
\hline $\begin{array}{l}\text { Analyzing } \\
\text { key } \\
\text { information }\end{array}$ & $\begin{array}{l}\text { Main ideas of the curriculum create a } \\
\text { macrostructure of the text, a skeleton } \\
\text { that makes work with information } \\
\text { easier / students are able to assess the } \\
\text { importance of information more } \\
\text { easily }\end{array}$ \\
\hline $\begin{array}{l}\text { Summarizing } \\
\text { information }\end{array}$ & $\begin{array}{l}\text { Reducing information } \\
\text { consolidated material into } \\
\text { corresponds to the original upon } \\
\text { critical analysis }\end{array}$ \\
\hline
\end{tabular}

\section{Concept Mapping}

We use various cognitive skills during concept mapping: representation, and generation and transformation of symbolic and linguistic information.

As [7] point out, almost no attention has been given to the methodology of using concept maps in the educational process. We also observe that the level of awareness on mapping is relatively low in Slovakia. The literature describes concept mapping most frequently as process-oriented teaching that represents not only acquiring knowledge but also systematically and conceptually how it is acquired. A constructivist understanding of teaching is determinant for using concept mapping in various phases of a lesson. If the students are systematically prepared to construct their knowledge, they will structure individual aspects of the map's potential content even when the teacher is presenting.

Based on reviewing the relevant literature, we characterize concept mapping as the creation of integrated schemes of structured relationships. Concept mapping organizes the logical structure of certain knowledge, and designs causal, mutual or final relational levels between a whole and its key components in cognition (idea, concept, hypothesis, principle). We consider concept mapping to be the culmination of the process of thinking. The map is stored in memory as a structure, which accumulates auditory and visual data on specific information together with models of effective action.
Concept mapping, in contrast to a linear structuring of information (also called traditional structuring in scientific literature), represents a system that supports how the human brain works. This statement is also supported by robust meta-analysis of the cognitive benefits of mapping [8]. Concept mapping is a natural technique, anchored in human thinking. It organizes information/knowledge and visualization of a data complex as well as its mutual interaction. Concept mapping brings new possibilities to the educational process. It allows us to look at the subject both holistically and analytically, bringing an innovative perspective to the subject and how it is structured or organized. Concept mapping in the educational process can help both the teacher and the student and their mutual interaction.

Only a handful of studies deal with including cognitive variables in the design and interpretation of concept maps. [9] in two experiments examined if and to what extent it is necessary to involve the working memory (system for coding, manipulation and retention of verbal and visual information) in processes of elaborating and interpreting a concept map. The studies showed a significant correlation between working memory and the final concept in the mind.

[10], [11] and others consider concept mapping to be an appropriate and important method for analysis and interpretation of students' mental representations. Concept mapping is a useful technique that helps effectively learn and organize received information in logical structures (among concepts, ideas, attachments, and associations). It helps to structure, analyze, synthesize, and generalize. Our review of the scientific literature brings us to the conclusion that, while there are no antagonistic explanations of the mapping concept, neither is there a uniformly accepted and empirically verified theoretical model of concept mapping.

\section{Research}

We believe that every concept and then idea should be primarily and profoundly internally consistent. There is not enough information in our contemporary schools on how students think. Therefore, further research needs to be organized on the organizing/structuring of students' knowledge and the modification of their internal knowledge system.

There are multiple reasons why we focus on introducing concept mapping into instruction. Primarily, we see its potential in improving current educational practice. Each student is unique and has his/her own preferred way of elaborating, organizing, retaining and presenting information. Our research aims at discovering the connection between how the teacher presents information, including prior didactical analysis of the subject, and the final representation of the subject by the student - shown through a concept map. 
We consider important not only the quantity of retained information but primarily whether students understood the presented information, can work with it, and interconnect related knowledge (as included in their internal knowledge structure). We identified the relational level of structuring the information and mental representations of students in history.

\section{Research Goal}

History is thought to be a subject that simply needs to be learned by heart. We are convinced there are methods and ways that explain information to students from history in a more understandable way, so they can easily interpret the information discussed and not rely on memorizing and empty verbalism.

Our main research goal was to analyze and compare the conceptual level of organizing information (curriculum) and its attachment to creation of mental representations in secondary students.

We examined how a selected type of information structuring, applied in facilitating the content of history, influences conceptualization of students' knowledge as reflected in a concept map.

Hypothesis H: Students who are presented information through non-linear organization reach a statistically higher level of factual accuracy than students who are presented information structured in a linear way.

\section{Sample Selection}

Professionals consider developmental psychology, specifically age disposition and students' competencies for mastering the curriculum, to be of critical importance for selection and organization of information. The learning capacity of students has limitation, which change in parallel with their development.

Secondary school students seemed to be the best pool for choosing the research group, since the students of this age reach a level of cognition when they can abstract, work with hypothetical reasoning, and think in general concepts and generalizations. The research sample consisted of 96 students in secondary grammar school (gymnasium) - four classes of the first year at a four-year secondary grammar school (gymnasium).

Considering the nature of the research and hypothesis, it was necessary to split the sample into control and experimental groups. In two classrooms (control groups), history was taught using linear organization of information - with frontal teaching as a dominant form. In two classrooms (experimental groups) we taught through non-linear methods, specifically using concept mapping. We constructed a concept map for every new topic for that purpose.
The map was used to deliver information on a given topic. One teacher taught all groups throughout the experiment (one of the authors of this article).

Table 3. Number of students

\begin{tabular}{|l|c|}
\hline \multicolumn{1}{|c|}{ Group } & No. of students \\
\hline Control group A & 26 \\
\hline Control group B & 23 \\
\hline Experimental group A & 23 \\
\hline Experimental group B & 24 \\
\hline
\end{tabular}

\section{Methodology}

To verify the efficacy of the change in the teaching method of choice - concept mapping - we used an experiment in natural environment of the secondary grammar school. We experimentally verified how a selected type of organizing information would influence students' mental representations.

We define structuring of information (explanation) as methods that facilitate content to the students. It is the ability of a teacher to create analogies between what is known to the students and the ideas of experts from various disciplines. When presenting curriculum to the students, teacher has to think about the structure of the content, and how to select key aspects of the curriculum and facilitate it to them, considering their mental and development level. The research period (covering a given thematic area) took 5 months.

Through a test of concept mapping we analyzed students' mental representations in a given thematic area. The evaluation of constructed maps was based on theoretical knowledge of concept mapping, but also actual construction of concept maps, in particular relational assessment of concept maps. We defined and analyzed the basic parameter of operationalization: factual accuracy. This parameter represents the informational completeness of a student's mental representation, identification of key concepts in individual topics, and the level of understanding of the concepts' content. We focused on specificity and the abstract character of the concepts, and their relevance and correctness.

The quality of concept maps was evaluated through IRT theory, specifically the correlated latent variable model [12]. The score of the constructs was then compared through the nonlinear alternative of one-factor multidimensional analysis of dispersion in relation to the group of students (control and experimental).

\section{Results and Discussion}

Consistency of concept maps was evaluated using a relational evaluation method through the ordinal variable factual accuracy on a scale from 1 to 5 (1 
being the lowest, 5 the highest). We complemented the collected statistical data with descriptive statistics of latent variables in Table No. 4. As one can see in Figure No. 1, students from the experimental group reached better evaluation in the examined indicator.

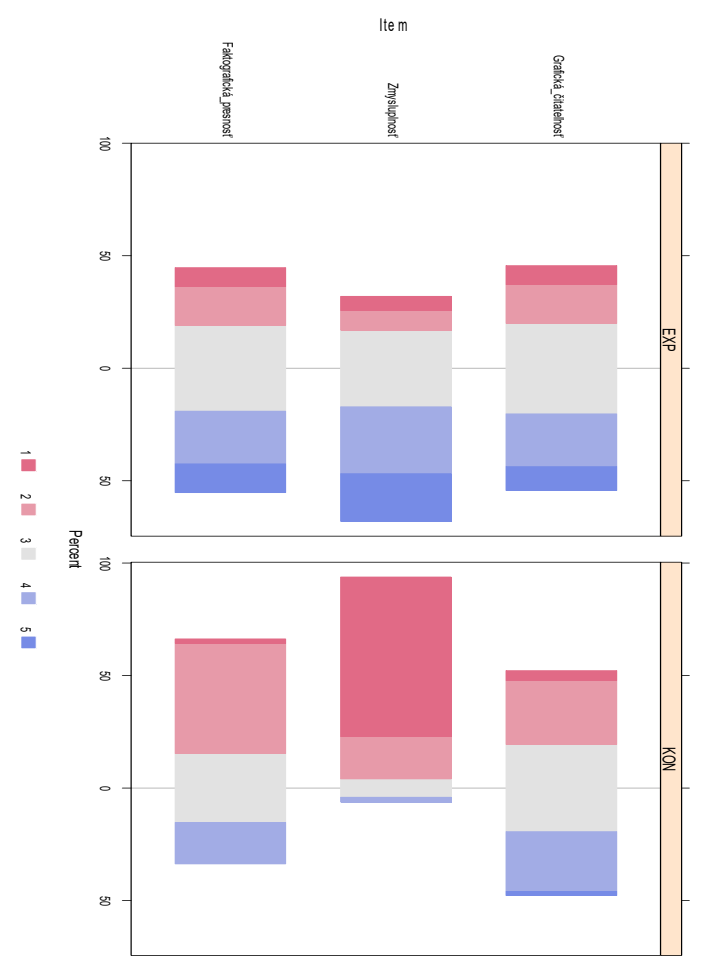

Figure 1. Relational evulation method

In most cases, students learn history mechanically, in order to remember all the facts and basic information. However, their learning is not meaningful. Our analysis compares the application of non-linear and linear structuring of information (selected thematic area) to their mental representations, recorded through concept mapping. Our results indicate that non-linear structuring is a more suitable strategy than linear structuring, which is primarily used in teaching history at secondary school.

The $\mathrm{H}$ hypothesis presumes that students that were presented information in non-linear structuring would reach a statistically significant higher level of factual accuracy than students that were presented information through linear structuring. We focused on identifying completeness of information and relevant identification of key concepts of the curriculum. The results indicate that students in experimental groups reached better results in the examined parameter.
When comparing results of the success rate in factual accuracy between the control and experimental group, we observed significant differences. We presumed that factual accuracy would be at the same level in both groups. While among students in experimental groups all scores are represented in given parameter $(1-5)$, no students of the control group achieved the highest score (5). That means that none of the students had a concept map complete from the informational perspective, with a high level of abstraction.

Among students in control groups there were often concepts unrelated to the thematic area, or concepts that would prove that students' understanding of the content was lacking. On the other hand, students in experimental groups had key concepts, and concepts with content corresponding to the thematic area (visualized in relations and hierarchies). Their maps were complete from the informational perspective, with a relatively high level of abstraction. Based on those results we can conclude that hypothesis $\mathbf{H}$ was confirmed.

\section{Conclusion}

To conclude, we believe that the educational content of history is extremely interesting and need not be a boring drill filled with facts. The basic prerequisite is that students just embrace, understand and remember information in a simple way.

The most important message from our point of view is for us to realize, in the context of educational practice, that students need to be taught within contexts, and not drilled on isolated facts. That is where we see the benefit and novelty of this paper.

The research confirms that changes in teaching methods - involving non-linear structured information - through concept mapping in facilitating information to the students has many benefits, leads to deeper understanding, helps systematize the content of education, enhances selfregulation of individual thinking, and enables visualization of mental representations.

Simultaneously, it makes possible the observation of gaps in understanding the curricula, allows reconstructing and modifying of information, and supports learning with comprehension.

\section{Acknowledgements}

The paper was developed with support under VEGA 1/0391/20 project Transformative Learning of the Student Teachers in the Context of Pupils'Critical Thinking Development. 


\section{References}

[1]. Petty, G. (1996). Moderní vyučování. 1. vyd. Praha. Portál, 380.

[2]. Malchiodi, C. A. (1998). Understanding children's drawings. Guilford Press.

[3]. Davido, R. (2001). Kresba jako nástroj poznání ditěte: dětská kresba z pohledu psychologie. Portál, sro.

[4]. Gagnon, G. W., \& Collay, M. (2005). Constructivist learning design: Key questions for teaching to standards. Corwin Press.

[5]. Dembo, M. H., \& Seli, H. (2012). Motivation and learning strategies for college success: A focus on self-regulated learning. Routledge

[6]. Ertmer, P. A., \& Newby, T. J. (2013). Behaviorism, cognitivism, constructivism: Comparing critical features from an instructional design perspective. Performance improvement quarterly, 26(2), 43-71. Retrieved form: http://onlinelibrary.wiley.com/doi/10.1002/piq.21143/ full [accessed: 17 May 2020.]
[7]. Bendl, S., \& Voňková, H. (2010). Využití pojmových map ve výuce pedagogiky. Pedagogická orientace, 20(1), 16-38.

[8]. Nesbit, J. C., \& Adesope, O. O. (2006). Learning with concept and knowledge maps: A metaanalysis. Review of educational research, 76(3), 413448.

[9]. Coluccia, E. (2008). Learning from maps: the role of visuo-spatial working memory. Applied Cognitive Psychology: The Official Journal of the Society for Applied Research in Memory and Cognition, 22(2), 217-233.

[10]. Kinchin, I. M. (2000). Concept-Mapping Activities To Help Students Understand Photosynthesis--and Teachers Understand Students. School Science Review, 82(299), 11-14.

[11]. Soyibo, K. (1995). Using concept maps to analyze textbook presentations of respiration. The American Biology Teacher, 57(6), 344-351.

[12]. Adams, R. J., Wilson, M., \& Wang, W. C. (1997). The multidimensional random coefficients multinomial logit model. Applied psychological measurement, 21(1), 1-23. 